University of Nebraska - Lincoln

DigitalCommons@University of Nebraska - Lincoln

\title{
Enteric bacteria of field-collected Colorado potato beetle larvae inhibit growth of the entomopathogens Photorhabdus temperata and Beauveria bassiana
}

\author{
Michael B. Blackburn \\ United States Department of Agriculture, mike.blackburn@ars.usda.gov \\ Dawn E. Gundersen-Rindal \\ United States Department of Agriculture \\ Donald C. Weber \\ United States Department of Agriculture \\ Phyllis A. W. Martin \\ United States Department of Agriculture \\ Robert R. Farrar Jr. \\ United States Department of Agriculture
}

Follow this and additional works at: https://digitalcommons.unl.edu/usdaarsfacpub

Part of the Agricultural Science Commons

Blackburn, Michael B.; Gundersen-Rindal, Dawn E.; Weber, Donald C.; Martin, Phyllis A. W.; and Farrar, Robert R. Jr., "Enteric bacteria of field-collected Colorado potato beetle larvae inhibit growth of the entomopathogens Photorhabdus temperata and Beauveria bassiana" (2008). Publications from USDAARS / UNL Faculty. 341.

https://digitalcommons.unl.edu/usdaarsfacpub/341

This Article is brought to you for free and open access by the U.S. Department of Agriculture: Agricultural Research Service, Lincoln, Nebraska at DigitalCommons@University of Nebraska - Lincoln. It has been accepted for inclusion in Publications from USDA-ARS / UNL Faculty by an authorized administrator of DigitalCommons@University of Nebraska - Lincoln. 


\title{
Enteric bacteria of field-collected Colorado potato beetle larvae inhibit growth of the entomopathogens Photorhabdus temperata and Beauveria bassiana
}

\author{
Michael B. Blackburn *, Dawn E. Gundersen-Rindal, Donald C. Weber, Phyllis A.W. Martin, Robert R. Farrar Jr. \\ Invasive Insect Biocontrol and Behavior Laboratory, Henry A. Wallace Beltsville Agricultural Research Center, Agricultural Research Service, \\ United States Department of Agriculture, Building 011A, Room 214, BARC-West, Beltsville, MD 20705, USA
}

\section{A R T I C L E I N F O}

\section{Article history:}

Received 31 January 2008

Accepted 19 May 2008

Available online 27 May 2008

\section{Keywords:}

Colorado potato beetle

Leptinotarsa decemlineata

Heterorhabditis marelatus

Photorhabdus temperata

Beauveria bassiana

\begin{abstract}
A B S T R A C T
The nematode Heterorhabditis marelatus fails to reproduce in the Colorado potato beetle, Leptinotarsa decemlineata, possibly due to interference from the enteric bacteria of the beetle. Specifically, the enteric bacteria inhibit the growth of Photorhabdus temperata, the enteric symbiont of the nematode, in vitro. However, previous work was based on a laboratory culture of $L$. decemlineata, and we wished to determine if similar bacteria were present in the field. Therefore, we cultured the enteric bacteria of fourthinstar larvae collected from the field at two locations in Maryland and Virginia. Representatives of the genera Pantoea, Enterobacter, Pseudomonas, Acinetobacter, Serratia, Stenotrophomonas, Curtobacterium, Bacillus, Lactococcus and Enterococcus were identified by sequencing of their $16 \mathrm{~S}$ rDNA. Isolates belonging to the genera Pantoea, Enterobacter, Pseudomonas, Serratia and Bacillus inhibited the growth of $P$. temperata. A number of these isolates also inhibited the entomopathogenic fungus Beauveria bassiana in vitro. Published by Elsevier Inc.
\end{abstract}

\section{Introduction}

The entomopathogenic nematode Heterorhabditis marelatus Liu and Berry and its bacterial symbiont, Photorhabdus temperata Fischer-Le Saux et al. are capable of killing the Colorado potato beetle, Leptinotarsa decemlineata (Say); however, the nematode is incapable of completing its reproductive cycle in the beetle (Armer et al., 2004). We recently examined both nematode vectored and artificially induced infection of $L$. decemlineata by $P$. temperata and found that $P$. temperata could not prevent spread and growth of the enteric bacteria within the host cadaver. In many cases the level of hemocoel contamination by other bacteria was substantial and could easily interfere with either the growth of $P$. temperata or its host nematode. In vitro growth-inhibition experiments demonstrated that many enteric isolates inhibited the growth of $P$. temperata but were not significantly inhibited by $P$. temperata (Blackburn et al., 2007).

The enteric bacteria of insects play a large and complex role in the biology of their hosts. Aside from the more obvious contribution to digestion and nutrition, the indigenous bacteria can displace or inhibit pathogenic species in a phenomenon termed "colonization resistance" (Dillon and Dillon, 2004). Although the competition $P$. temperata appears to encounter when colonizing $L$. decemlineata is distinct from colonization resistance in that it does not prevent disease in an individual, it does represent a plau-

\footnotetext{
* Corresponding author. Fax: +1 3015045104.

E-mail address: mike.blackburn@ars.usda.gov (M.B. Blackburn).
}

sible mechanism for inhibiting the establishment of a pathogen in a population.

Our previous experiments were conducted on a laboratory colony of $L$. decemlineata whose gut microbiota might not reflect that of field populations. Thus, we wished to sample field-collected L. decemlineata to determine how their enteric bacteria differed from our laboratory colony, and to determine if these bacteria inhibit P. temperata or the entomopathogenic fungus Beauveria bassiana (Balsamo) Vuillemin.

\section{Materials and methods}

\subsection{Bacterial isolation and culture}

All bacteria described in this study were isolated and grown on solid medium consisting of $2 \%$ Bacto $^{\circledR}$ Proteose Peptone \#3 (PP3) in 1.6\% Bacto ${ }^{\circledR}$ agar (both obtained from Becton Dickinson and Co., Sparks, MD, USA). Liquid cultures were grown in 2\% PP3. The choice of media obviously affects which bacteria can be isolated from a given source. Since our primary objective was to assess the effect of enteric species on the growth of $P$. temperata, we chose PP3 because we are familiar with the behavior of $P$. temperata on this medium.

Bacteria were isolated from apparently healthy fourth-instar L. decemlineata collected from potato at the Beltsville Agricultural Research Center (Beltsville, MD, USA) and from the Virginia Tech Eastern Shore Agricultural Research and Extension Center (Painter, VA, USA). Collections were made on two separate occasions at both sites in May and June 2007. 
Larvae were placed in sterile $50 \mathrm{ml}$ plastic centrifuge tubes that were placed in a horizontal position. When larvae defecated, $5 \mu \mathrm{l}$ of fluid was pipetted from the frass and used for inoculations. In cases where $5 \mu$ l could not be recovered, $10 \mu$ of sterile PP3 medium was pipetted onto the frass, mixed, and $5 \mu \mathrm{l}$ of the excess fluid recovered for inoculation. In the first collections from each site, the fluid was used to inoculate $100 \mathrm{ml}$ of PP3 in a 500-ml flask, which was then shaken at $250 \mathrm{rpm}$ for $24 \mathrm{~h}$ at $25^{\circ} \mathrm{C}$. At $24 \mathrm{~h}$, serial dilutions of the cultures were prepared with sterile PP3, and $10 \mu \mathrm{l}$ aliquots of selected dilutions spread on 100-mm plates of PP3 agar. Apparent single colony isolates were selected from these plates after 48$72 \mathrm{~h}$ for sub-culturing. For some samples from the first Beltsville collection and all samples from the second collections at each site, serial dilutions of the fluid recovered from frass were spread directly onto plates.

Bacterial isolates from individual larvae were chosen for further analysis based on colony morphology and appearance. We were less concerned with the relative abundance of different bacteria than we were with generating a reasonably accurate picture of the spectrum of bacterial species that could be cultured, albeit on PP3 alone, from the beetle larvae. All colonies that appeared unique or occurred at low frequency were retained for further study. When many colonies appeared to be of the same type, a number of these apparently identical isolates were retained. All isolates were maintained in culture on PP3 agar and were sub-cultured bi-weekly.

\subsection{Identification of bacteria}

Individual enteric bacterial isolates were identified by PCR amplification and sequencing of conserved 16S ribosomal DNAs. For each isolate, DNA was purified from $2 \mathrm{ml}$ of liquid culture. DNA was isolated using the Quantum Prep miniprep kit (BioRad, Hercules, CA, USA) as specified by the manufacturer for use as template in polymerase chain reaction (PCR). Nearly full length $16 \mathrm{~S}$ rDNA was amplified for each isolate using primers universal to prokaryotes, R16F0 and R16R0 (Lee et al., 1993). Thirty-five PCR cycles were conducted in a model 9700 thermocycler (Applied Biosystems, Foster City, CA, USA) using $30 \mathrm{~s}$ denaturation at $94^{\circ} \mathrm{C}$, 1.5-min annealing at $55^{\circ} \mathrm{C}$ and 2-min primer extension (10 min in final cycle) at $72{ }^{\circ} \mathrm{C}$. Bacterial 16S rDNA amplicons were sequenced directly. Products were separated on $1.5 \%$ NuSieve agarose gel (FMC, Rockland, ME, USA) in modified-1X TAE (0.04 M Tris-acetate and 0.1 mM EDTA), and excised for sequencing using ABI BigDye V1.1 (Applied Biosystems with both amplification primers and a nested universal primer 533F: 5'-GTGCCA GCMGCCGCGGTAA-3'). Cycle sequencing conditions were 35 cycles at $96{ }^{\circ} \mathrm{C}, 10 \mathrm{~s} ; 50{ }^{\circ} \mathrm{C}, 5 \mathrm{~s} ; 60^{\circ} \mathrm{C}$ for $4 \mathrm{~min}$. Automatic sequencing was carried out on an ABI Prism Model 3100 (Applied Biosystems). Sequences of $16 \mathrm{~S}$ rDNAs were edited and assembled (DNASTAR, SeqMan component) and compared with those of known bacteria using BLAST searches (Altschul et al., 1990).

\subsection{Phylogenetic analysis}

Preliminary assignment of bacterial isolate $16 \mathrm{~S}$ rDNA sequences to phylogenetic groups was performed by comparing them with sequences of bacterial type strains using the Seqmatch tool from the Ribosomal Database Project-II (Cole et al., 2005). Phylogenetic analyses were undertaken to examine relationships among new isolates preliminarily assigned to (1) Enterobacteriaceae, and to (2) Pseudomonas groups. 16S rDNA sequences from the new bacterial isolates and type strain sequences from closely related bacteria were aligned separately using the CLUSTAL W algorithm of the MegAlign component of the Lasergene suite (DNASTAR, Inc., Madison, WI, USA). Phylogenetic analyses were performed using PAUP version 4.10b (Sinauer Associates, Sunderland, MA, USA). Uninformative characters were excluded from analyses. Phylogenetic trees were constructed by heuristic search via random stepwise addition and TBR branch swapping to find the optimal phylogenetic tree(s). Xanthemonas campestris (Pammel) Dowson and Yersinia enterocolitica (Schliefstein and Coleman) Frederiksen were designated outgroups to root the Pseudomonas and Enterobacteriaceae trees, respectively.

\subsection{Bacterial growth experiments}

The growth of 12 selected enteric isolates in the presence of the primary phase of $P$. temperata, and their effect on the growth of $P$. temperata, were examined as described by Martin (2002). Briefly, interactive effects on the growth of two isolates of bacteria were evaluated by measuring the widths of two parallel lines of bacteria streaked on a single agar plate. Primary phase $P$. temperata isolated from $H$. marelatus and maintained on PP3 agar (Blackburn et al., 2007) was used. Two sets of $100 \mathrm{~mm}$ plates of PP3 agar were included. On the first set, one streak of an enteric bacterium was paired with one streak of $P$. temperata $1 \mathrm{~cm}$ apart. The second set of plates served as controls, with two streaks of the same bacterium on the same plate. Plates were incubated at $25^{\circ} \mathrm{C}$ for $72 \mathrm{~h}$. A stereomicroscope equipped with a calibrated ocular micrometer was used to measure the width of each streak in the first set of plates at five pre-determined points. These five measurements were then averaged to obtain a single value for each streak. One of the two streaks on each control plate was measured similarly. The test was replicated four times.

The widths of the streaks of enteric isolates paired with P. temperata were compared to the widths of their respective control streaks by factorial analysis of variance (ANOVA; PROG GLM, SAS Institute, 2006) with isolate and pairing (with $P$. temperata or with itself) as main effects. The widths of each enteric isolate were also compared individually with their respective controls. The widths of streaks of $P$. temperata were analyzed similarly. The width of each enteric isolate was also expressed as a proportion of the width of its control streak. These data were analyzed by ANOVA for effects of enteric isolate, and means were separated by the least significant difference (LSD) test. Widths of streaks of $P$. temperata were also analyzed in this manner. Lastly, a test for correlation between the absolute widths of the streaks of the enteric isolates with the widths of their respective $P$. temperata streaks was performed (PROC CORR, SAS Institute, 2006). In all analyses, each plate was treated as a replicate.

\subsection{Fungal growth experiments}

Starter cultures of 15 selected enteric bacteria were prepared by streaking $60-\mathrm{mm}$ plates (48 $\mathrm{mm}$ inside diameter) of PP3 and incubating them at $24^{\circ} \mathrm{C}$ for $24 \mathrm{~h}$. Clean plates of PP3 were then inoculated with $B$. bassiana (ARSEF 6721) by pipetting $10^{4}$ conidia in $10 \mu \mathrm{l}$ of $10 \%$ glycerol in water onto each plate. A sterile plastic spreader was used to evenly distribute conidia across the plate. To inoculate plates with bacteria, a sterile 6 - $\mathrm{mm}$ paper disk (Becton, Dickinson and Co.) was pressed onto the starter plate of each isolate. The disk was then pressed onto the center of a plate with $B$. bassiana conidia, then removed and discarded. Plates without $B$. bassiana were similarly inoculated with each bacterial isolate. In addition, three plates inoculated with conidia only and one uninoculated plate were included. Plates were incubated at $24^{\circ} \mathrm{C}$. The test was replicated four times.

Seven days after inoculation, the density of fungal growth was rated visually. A scale of $0-4$ was used, where zero was no fungal growth visible to the unaided eye and four was fungal growth similar to that on plates inoculated with B. bassiana only. At this time, 
the diameter of the zone of bacterial growth was also measured. Density data were $\sqrt{ } \mathrm{x}+0.5$ transformed prior to statistical analysis, but means presented are of untransformed data. Density data were analyzed by ANOVA for effects of bacterial isolate. Ratings of uninoculated plates and plates inoculated with B. bassiana only were included as controls. Means were separated by LSD. Diameters of the bacterial zones were analyzed by ANOVA for effects of isolate, fungus treatment (i.e., with versus without $B$. bassiana) and the interaction thereof. A test for correlation between fungal density and bacterial zone diameter was also performed. Treatments of $B$. bassiana only and uninoculated plates were not included in analyses of bacterial zone diameter.

\section{Results}

\subsection{Identification of bacteria}

In all, 76 bacterial isolates were identified to genus level from a total of 20 larvae collected from the two sites (Table 1). The most prevalent types of bacteria isolated from both sites were from the closely related genera Enterobacter (29 isolates) and Pantoea (15 isolates), with Acinetobacter (12 isolates) and Pseudomonas (10 isolates) also occurring frequently. Other types of bacteria whose occurrence appeared more incidental belonged to the genera Bacillus ( 3 isolates), Lactococcus (2 isolates), Curtobacterium (2 isolates), Serratia (1 isolate), Stenotrophomonas (1 isolate) and Enterococcus (1 isolate). The 16S rDNA sequences of representative isolates have been deposited in GenBank (Accession Nos. EU693534-EU693575).

Phylogenetic relationships among new isolates and type strain Enterobacteriaceae (Pantoea, Enterobacter and Serratia) based on 16S rDNA sequences are shown in Fig. 1, while analysis of Pseudomonas isolates is presented in Fig. 2. Phylogenetic analysis of $16 \mathrm{~S}$ rDNA sequences revealed that the new Enterobacter isolates were of two lineages. New Enterobacter isolates 2B1C, 2B1E, 2B2A 2B2B, 2B2C, 2B2D, 2B5C, 2B5D, 2B5E, 2B8D and 2V4A formed a monophyletic clade with closely related characterized Enterobacter asburiae Brenner et al. and Enterobacter cancerogenus (Urosevic) Dickey and Zumoff; new Enterobacter isolates 2B7A, 2B7B, 2B8C, $2 \mathrm{~V} 2 \mathrm{~A}$ and $2 \mathrm{~V} 5 \mathrm{~B}$ grouped with the characterized species $E$. ludwigii Hoffman et al. (Fig. 1). All Pantoea-related isolates (2V1E1A, 2V2D2, 2B8A, 2B4D, 2B7C, 2B7D and 2B7E) formed a monophyletic clade with the two type species strains of $P$. agglomerans (Ewing and Fife) Gavini (Fig. 1). The sole Serratia isolate 2V1A was most closely related to characterized species Serratia marcescens Bizio (Fig. 1). Phylogenetic analysis of 165 rDNA sequences revealed that the new Pseudomonas isolates were also of two lineages. New Pseudomonas isolates B3G and 2V1D were closely related to characterized species Pseudomonas koreensis Kwon et al., while isolates 2B5A, 2B5B, BD3E, 2V1C, 2V2E and 2V2F all grouped within the large clade containing characterized species Pseudomonas putida (Trevisan) Migula, Pseudomonas fulva Iizuki and Komagata, Pseudomonas oryzihabitans Kodama et al., Pseudomonas entomophila, Pseudomonas plecoglossicida Nishimori and other characterized Pseudomonas species (Fig. 2).

\subsection{Bacterial growth experiments}

Results of bacterial growth experiments scored at $72 \mathrm{~h}$ are shown in Fig. 3. As a group, the growth of the enteric isolates next to $P$. temperata appeared to be stimulated $(F=16.28$; $\mathrm{df}=1,68$; $P=0.0001$ ); however, on an individual basis, none of the isolates were significantly stimulated $(P>0.05)$. Growth of $P$. temperata next to the enteric isolates was significantly suppressed, both as a group, and in most individual comparisons. The only isolates that did not significantly inhibit $P$. temperata were Pantoea 2B7D, Stenotrophomonas $2 \mathrm{~V} 2 \mathrm{H}$ and Acinetobacter 2V3A; the latter significantly stimulated growth of $P$. temperata. There were substantial differences in absolute growth among the enteric isolates, and there was a weak but significant negative correlation between the width of the $P$. temperata streaks and the width of the enteric isolate streaks $(r=-0.3130, P=0.0342)$. Width of the enteric isolate streaks as a proportion of their controls did not vary among isolates $(F=1.77 ; \mathrm{df}=11,31 ; P=0.1036)$. In $P$. temperata, this proportion was affected by the enteric isolate with which it was paired $(F=8.77 ; \mathrm{df}=11,31 ; P=0.0001)$. In the latter case, Acinetobacter isolate 2V3A differed significantly $(P<0.05)$ from the other isolates by LSD.

\subsection{Fungal growth experiments}

Fungal density was significantly affected by bacterial isolate $(F=47.16 ; \mathrm{df}=16,56 ; P=0.0001)$ (Fig. 4). Pseudomonas isolates B3G and 2V1D completely inhibited fungal growth, with no visible growth on any plate. A third isolate, Enterobacter 2B1C, consistently reduced fungal growth to low levels. The LSD indicated that all the isolates inhibited fungal growth except Pantoea isolates 2B7D, 2B4D and 2B7C, which did not differ from the treatment of

Table 1

Phylogenetic grouping of 165 rDNA sequences from representative Leptinotarsa decemlineata isolates

\begin{tabular}{|c|c|c|}
\hline Nearest type strain & Type strain accession nos. & L. decemlineata isolate (\% identity) \\
\hline \multicolumn{3}{|l|}{ Bacilli } \\
\hline Bacillus cereus ATCC 14579 & AF290547 & B2A (99.0) \\
\hline Lactococcus lactis subsp. cremoris ATCC 19257 & M58836 & 2V3B (99.5), 2V2C (98.8) \\
\hline Enterococcus casseliflavus NCIMB 11449 & Y18161 & $2 \mathrm{~V} 5 \mathrm{C}(99.7)$ \\
\hline \multicolumn{3}{|l|}{$\gamma$-Proteobacteria } \\
\hline Pantoea agglomerans NCTC9381T & AJ251466 & 2V1E1A (100), 2V2D2 (100) \\
\hline Pantoea agglomerans ATCC 27155 & AF130953 & 2B7D (99.8), 2B4D (98.8) \\
\hline Enterobacter asburiae JCM6051 & AB004744 & 2B5D (99.7), 2B1C (100) \\
\hline Enterobacter cancerogenus LMG2693 & Z96078 & 2B2B (99.9), 2B2C (99.7), 2V4A (99.8) \\
\hline Enterobacter ludwigii DSMZ 16688 & AJ853891 & 2V5B (99.8), 2V2A (99.7), 2B7B (99.6) \\
\hline Pseudomonas koreensis Ps 9-14 & F468452 & B3G (99.8), 2V1D (99.6) \\
\hline Pseudomonas parafulva AJ 2129T & AB060132 & В3С (99.9), 2В5В (99.8) \\
\hline Pseudomonas oryzihabitans IAM1568 & D84004 & 2V1C (99.3) \\
\hline Pseudomonas plecoglossicida FPC951 & AB009457 & BD3E (99.6), 2V2F (99.7) \\
\hline Acinetobacter calcoaceticus NCCB 22016 & AJ888983 & 2V3A (99.8), 2V2D1 (100) \\
\hline Serratia marcescens subsp. marcescens ATCC 13880 & M59160 & $2 \mathrm{~V} 1 \mathrm{~A}(99.9)$ \\
\hline Stenotrophomonas maltophilia ATCC 13637T & AB008509 & $2 \mathrm{~V} 2 \mathrm{H}(99.0)$ \\
\hline \multicolumn{3}{|l|}{ Actinobacteria } \\
\hline Curtobacterium flaccumfaciens pv. flaccumfaciens LMG 3645 & AJ312209 & 2B4A (99.6) \\
\hline
\end{tabular}




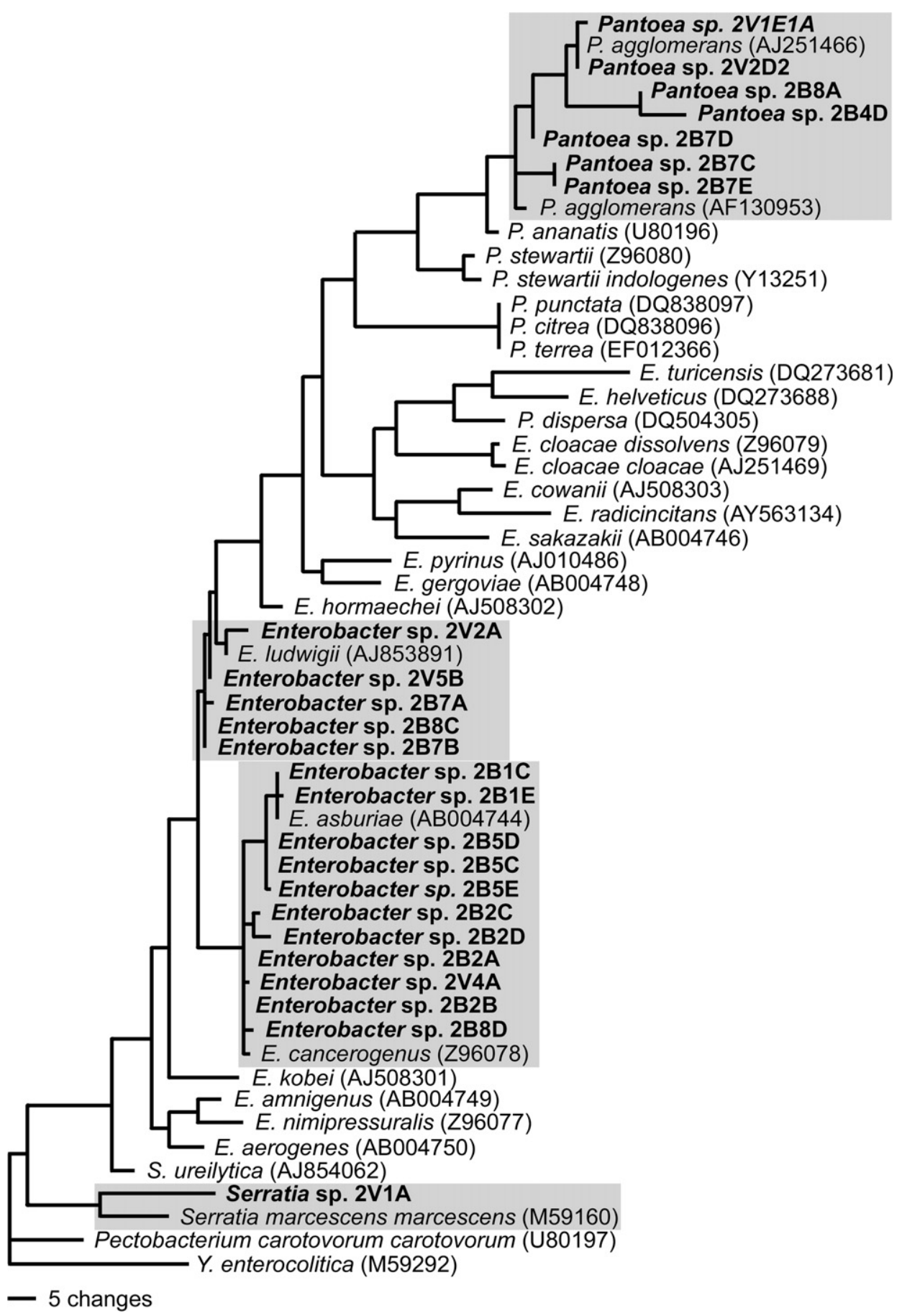

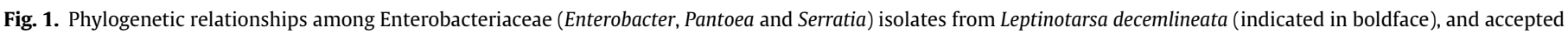
type strains from these genera.

B. bassiana alone. The diameter of the bacterial zone varied significantly among isolates ( $F=27.94 ; \mathrm{df}=14,87 ; P=0.0001)$ but was not affected by the presence or absence of $B$. bassiana $(F=0.12$; $\mathrm{df}=1,87 ; P=0.7286$ ) or by the interaction of isolate and fungus treatment $(F=0.26 ; \mathrm{df}=1,87 ; P=0.9964)$. There was a significant negative correlation between diameter of the bacterial zone and fungal density $(r=-0.8710, P=0.0001)$.

\section{Discussion}

Blackburn et al. (2007) found that infection of laboratory-reared $L$. decemlineata larvae by $P$. temperata typically resulted in a mixed culture of bacteria within the insect cadaver, regardless of whether the infection was vectored by the nematode $H$. marelatus or by injection. Enteric species isolated from these larvae belonging to the genera Pantoea, Pseudomonas, Acinetobacter, Serratia and Klebsiella were able to inhibit the growth of $P$. temperata to a greater extent than $P$. temperata was able to inhibit their growth. In the current study we have cultured bacteria from field-collected L. decemlineata and found representatives of the genera Pantoea, Enterobacter, Pseudomonas, Acinetobacter, Serratia, Stenotrophomonas, Curtobacterium, Bacillus, Lactococcus and Enterococcus. Results of growth-inhibition experiments conducted on $P$. temperata in the current study are similar to those of the previous study; many 


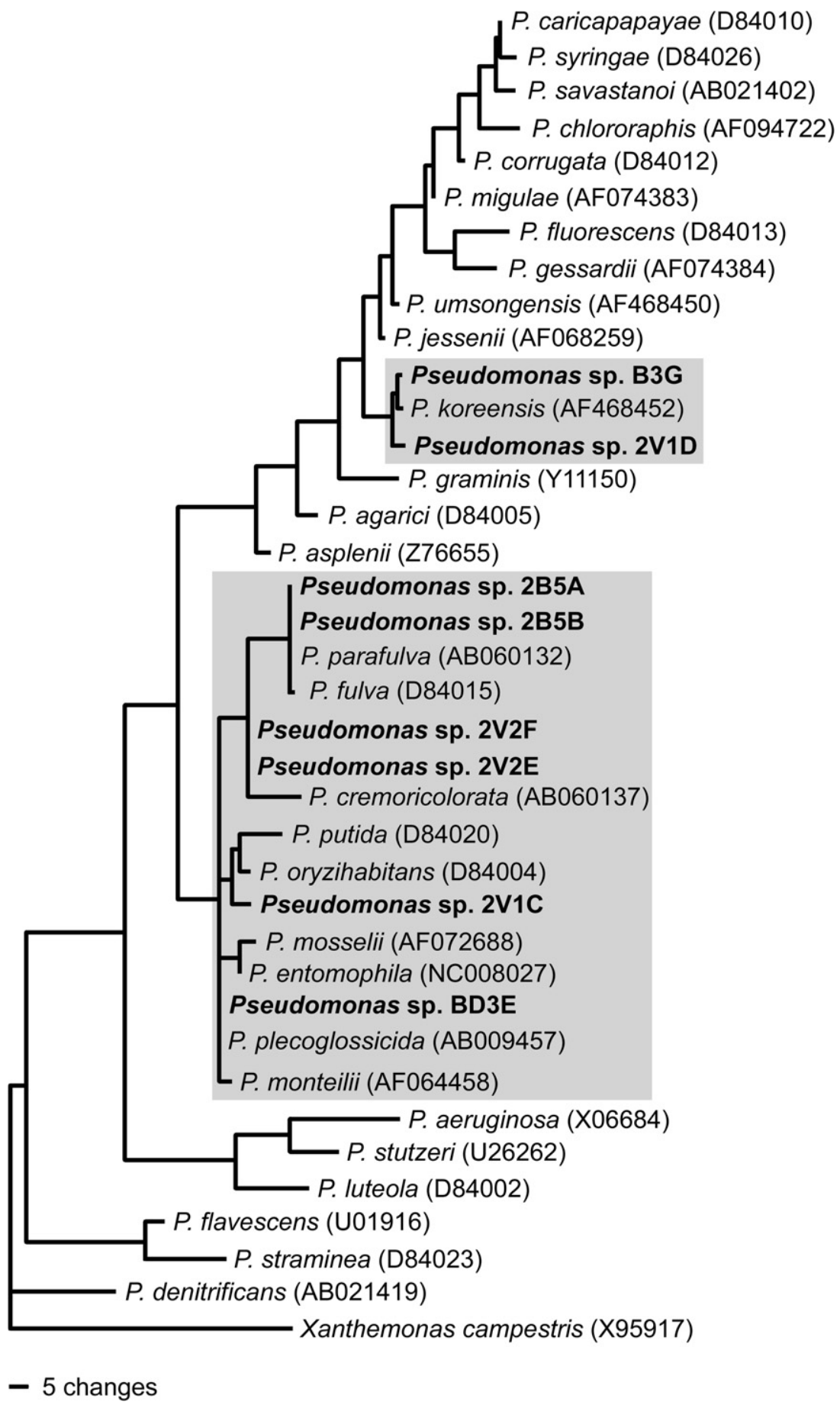

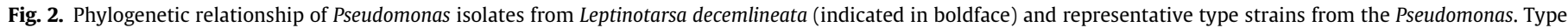
strains were chosen to represent the major phylogenetic groups of the Pseudomonas as described by Anzai et al. (2000).

enteric isolates inhibited $P$. temperata to a greater extent than $P$. temperata inhibited them. In fact, as a group, the enteric isolates that we tested were stimulated by $P$. temperata. Only three of 12 isolates tested did not significantly inhibit $P$. temperata: Acinetobacter 2V3A, Stenotrophomonas 2V2H and Pantoea 2B7D. Curiously, Acinetobacter $2 \mathrm{~V} 3 \mathrm{~A}$ actually stimulated $P$. temperata.

Isolates representing the genera Pseudomonas, Enterobacter and Serratia also inhibited the growth of the entomopathogenic fungus $B$. bassiana in vitro. In particular, Pseudomonas isolates B3G and 2V1D were found to completely inhibit the growth of $B$. bassiana. In contrast, the Pantoea isolates that we tested had little effect on the fungus.
With the exception of Lactococcus and Enterococcus, representatives of all the genera found in the frass of $L$. decemlineata have been demonstrated to be endophytes of potato (Sturz and Matheson, 1996; Sturz et al., 1998; Garbeva et al., 2001; Reiter et al., 2002; Sessitsch et al., 2004; Berg et al., 2005), suggesting that the culturable gut flora of $L$. decemlineata larvae may be largely determined by the endophytic community of the host plant.

Among those bacteria that we could culture from larval frass, the most commonly isolated were species of the closely related genera Enterobacter and Pantoea. Based on 16S rDNA sequence comparisons with accepted type strains, the closest matches were for P. agglomerans, E. asburiae, E. cancerogenus and E. ludwigii. Both 


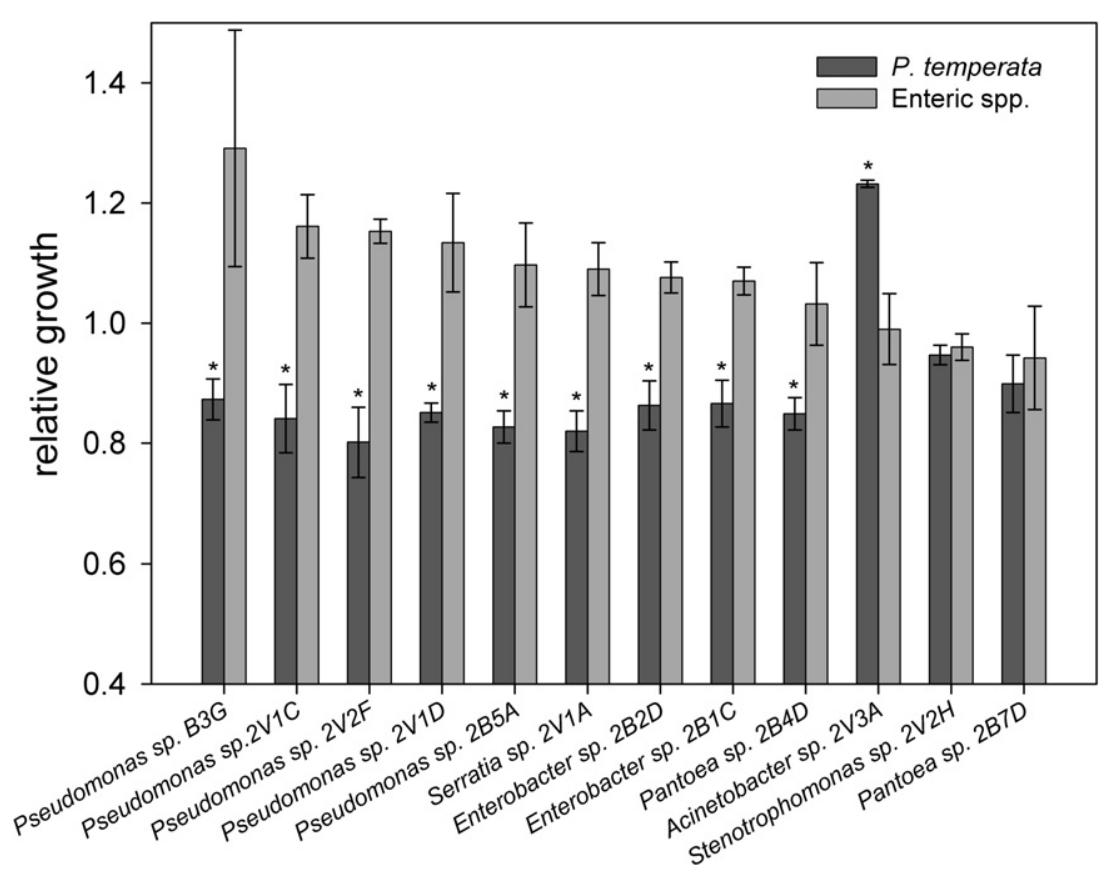

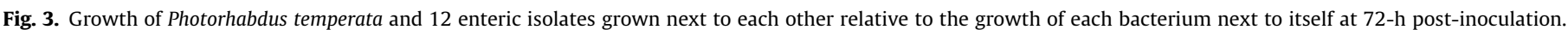
Asterisks indicate growth significantly different $(P<0.05)$ from that of controls.

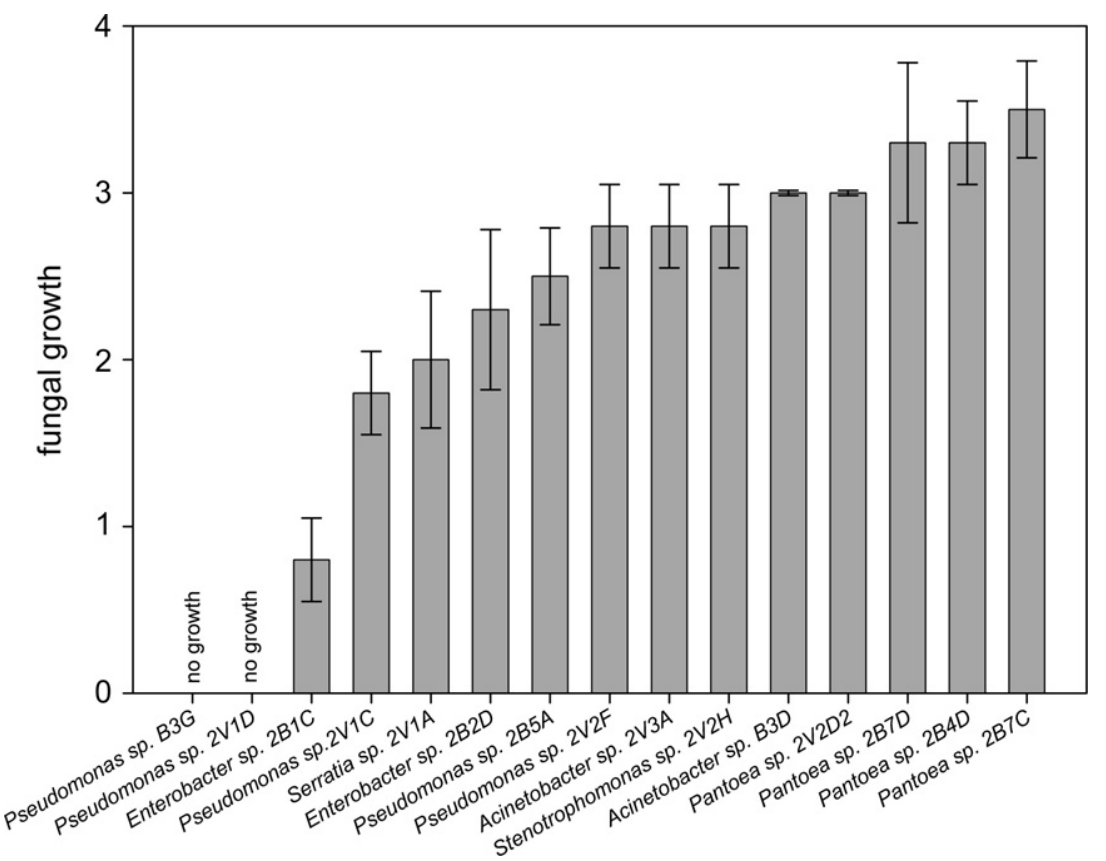

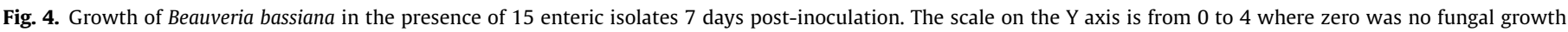
visible to the unaided eye and four was fungal growth similar to that on plates inoculated with $B$. bassiana only.

P. agglomerans and E. cancerogenus have specifically been cited as potato endophytes (Sturz and Matheson, 1996; Garbeva et al., 2001; Sessitsch et al., 2004), while E. asburiae has been shown to be associated with a variety of other plants (Asis and Adachi, 2003). Pantoea agglomerans and Enterobacter spp. have also been isolated or identified from diverse insect species (Dillon and Charnley, 1995; Broderick et al., 2004; Vasanthakumar et al., 2006; Dunn and Stabb, 2005; Nishiwaki et al., 2007; Blackburn et al., 2007). In the only prior study of the enteric bacteria of L. decemlineata, Steinhaus (1941) apparently reported members of the genera Pantoea and Enterobacter as Flavobacterium acidificum sp. nov. and Aerobacter aerogenes, respectively. Aerobacter aerogenes is synonymous with the current Enterobacter aerogenes Hormaeche and Edwards, and $F$. acidificum was considered by Holmes et al. (1984) to be identical to Erwinia ananas Serrano, which is now classified as Pantoea ananatis (Serrano) Mergaert et al.

In both plants and insects, $P$. agglomerans appears to offer its host some protection from colonization by both fungal and bacterial pathogens. It has been shown to inhibit Erwinia amylovora (Burrill) Winslow, the causative agent of fire blight (Wright et al., 
2001) and has been shown to inhibit growth of several fungal pathogens on tomato (Enya et al., 2007). In the desert locust, Schistocerca gregaria (Forskal), P. agglomerans has been shown to be involved in the production of anti-fungal phenols that inhibit Metarhizium anisopliae (Metschnikov) Sorokin (Dillon and Charnley, 1995) and, with other gut bacteria, to resist colonization by S. marcescens (Dillon et al., 2005). We found that one of two Pantoea isolates and both of the Enterobacter isolates we tested significantly inhibited $P$. temperata. These same Pantoea isolates had little or no effect on the growth of B. bassiana; however, Enterobacter isolate 2B1C strongly inhibited the fungus. The failure of Pantoea isolates to inhibit $B$. bassiana in the present study may be due to the absence of plant material in our assays that might be necessary for the production of anti-microbial phenolics (Dillon and Charnley, 1995).

Phylogenetic analysis of 165 rDNA sequences from our Pseudomonas isolates, together with sequences from type strains representing major groups of the Pseudomonas sensu stricto (Anzai et al., 2000) suggests two groups. Most of the isolates are clustered within the $P$. putida group, with $16 \mathrm{~S}$ rDNA sequences that most closely resembled either Pseudomonas parafulva Uchino, $P$. oryzihabitans or $P$. plecoglossicida. Pseudomonas putida and closely related members of this group have been repeatedly reported as endophytes of potato (Sturz et al., 1998; Garbeva et al., 2001; Reiter et al., 2002; Sessitsch et al., 2004; Berg et al., 2005), and Steinhaus (1941) reported "Pseudomonas ovalis Chester" from $L$. decemlineata, a bacterium presumed by Palleroni (1984) to be P. putida. A second group, isolated from both sampling sites, most closely resembles $P$. koreensis Kwon et al., a recently described species isolated from agricultural soils in Korea (Kwon et al., 2003). Bacteria with 16 S rDNA sequences highly similar to $P$. koreensis have been isolated from both ginseng and tomato, and shown to inhibit phytopathogenic fungi (Cho et al., 2007; Enya et al., 2007). Interestingly, both of the Pseudomonas isolates from this group (B3G and 2V1D) were the most potent inhibitors of $B$. bassiana that we found, and both inhibited $P$. temperata as well. As a group, the Pseudomonas isolates displayed the greatest inhibitory activity against both entomopathogens.

In our prior study, a strain of $S$. marcescens associated with our laboratory colony of $L$. decemlineata was found to strongly inhibit $P$. temperata. We were only able to obtain a single putative isolate of $S$. marcescens from field-collected larvae, suggesting that this species occurs only sporadically in agricultural settings. However, this isolate did inhibit both $P$. temperata and B. bassiana.

The term colonization resistance refers to the concept that the normal gut flora is capable of inhibiting the growth of pathogens and affords the individual host a degree of protection from disease, but in a broader sense the idea can be extended to populations. Blackburn et al. (2007) described a possible example of colonization resistance operating at the level a population. Although the nematode $H$. marelatus and its symbiont $P$. temperata were capable of killing $L$. decemlineata, it appeared that P. temperata was incapable of excluding the gut bacteria from propagating within the host cadaver to the extent that Photorhabdus spp. can in other insects, leading to reproductive failure of the nematode. When the effectiveness or persistence of a control agent is at least partially dependent on reproduction within the host, if reproduction is inhibited, the host population will benefit even though individual hosts may die. In the present study, we have examined field-collected $L$. decemlineata and found that their enteric flora includes many species that inhibit $P$. temperata in vitro. Some of these same isolates also have inhibitory effects on the growth of the entomopathogenic fungus $B$. bassiana. Although replication of B. bassiana in the target insect may be less crucial for persistence in the field, the enteric bacteria may still offer the beetles some resistance to infection. In addition to inhibiting the growth of ingested conidia, foliage surfaces of plants infested with $L$. decemlineata, and the insects them- selves, are generally contaminated by frass. Surface contamination by the enteric bacteria, or their metabolites, may inhibit the germination and growth of $B$. bassiana across the cuticle or trachea. Regarding this last point, it should be noted that certain chrysomelid beetles, such as Lema trilinea White, form shields of fecal matter on their backs. While this has been correctly interpreted as a defense against predation (Morton and Vencl, 1998), it is also possible that the bacteria or bacterial metabolites contained in these fecal masses protect the larvae from pathogens, and it would be worthwhile to investigate the relative susceptibility of species forming such shields to pathogens.

The concept of biological control is based on principles of population dynamics. In the best case, a pest population is regulated by the density-dependent action of predators, parasitoids or pathogens. Although current understanding of the population dynamics of plant endophytes and the enteric bacteria of insects is very limited, it is clear that these bacterial communities constitute potentially potent antagonists to bacterial or fungal biological control agents.

\section{Acknowledgments}

Many thanks to Thomas Kuhar of the Virginia Tech Eastern Shore Agriculture Research and Extension Center for supplying us with $L$. decemlineata larvae, and to Ashaki Mitchell for technical assistance. Mention of a trademark or proprietary product does not constitute a guarantee or warranty of the product by the USDA and does not imply its approval to the exclusion of other products that may also be suitable.

\section{References}

Altschul, S.F., Gish, W., Miller, W., Myers, E.W., Lipman, D.J., 1990. Basic local alignment search tool. Journal of Molecular Biology 215, 403-410.

Anzai, Y., Hongik, K., Park, J.Y., Oyaizu, H., 2000. Phylogenetic affiliation of pseudomonads based on 16S rRNA sequences. International Journal of Systematic and Evolutionary Microbiology 50, 1563-1589.

Armer, C.A., Berry, R.E., Reed, G.L., Jepsen, S.J., 2004. Colorado potato beetle control by application of the entomopathogenic nematode Heterorhabditis marelatus and potato plant alkaloid manipulation. Entomologia Experimentalis et Applicata 111, 47-58.

Asis, C.A., Adachi, K., 2003. Isolation of endophytic diazotroph Pantoea agglomerans and nondiazotroph Enterobacter asburiae from sweetpotato stem in Japan. Letters in Applied Microbiology 38, 19-23.

Berg, G., Krechel, A., Ditz, M., Sikora, R.A., Ulrich, A., Hallmann, J., 2005. Endophytic and ectophytic potato-associated bacterial communities differ in structure and antagonistic function against plant pathogenic fungi. FEMS Microbiology Ecology 51, 215-229.

Blackburn, M.B., Farrar, R.R., Gundersen-Rindal, D.E., Martin, P.A.W., Lawrence, S.D., 2007. Reproductive failure of Heterorhabditis marelatus in the Colorado potato beetle: evidence of stress on the nematode symbiont Photorhabdus temperata and potential interference from the enteric bacteria of the beetle. Biological Control 42, 207-215.

Broderick, N.A., Raffa, K.F., Goodman, R.M., Handelsman, J., 2004. Census of the bacterial community of the gypsy moth larval midgut by using culturing and culture-independent methods. Applied and Environmental Microbiology 70, 293-300.

Cole, J.R., Chai, B., Farris, R.J., Wang, Q., Kulam, S.A., McGarrell, G., Garrity, G.M., Tiedje, J.M., 2005. The Ribosomal Database Project (RDP-II): sequences and tools for high-throughput rRNA analysis. Nucleic Acids Research 33, D294-D296.

Cho, K.M., Hong, S.Y., Lee, S.M., Kim, Y.H., Kahng, G.G., Lim, Y.P., Kim, H., Yun, D.Y., 2007. Endophytic bacterial communities in ginseng and their antifungal activity against pathogens. Microbial Ecology 54, 341-351.

Dillon, R.J., Charnley, A.K., 1995. Chemical barriers to gut infection in the desert locust-in vivo production of antimicrobial phenols associated with the bacterium Pantoea agglomerans. Journal of Invertebrate Pathology 66, 72-75.

Dillon, R.J., Dillon, V.M., 2004. The gut bacteria of insects: non-pathogenic interactions. Annual Review of Entomology 49, 71-92.

Dillon, R.J., Vennard, C.T., Buckling, A., Charnley, A.K., 2005. Diversity of locust gut bacteria protects against pathogen invasion. Ecology Letters 8, 1291-1298.

Dunn, A.K., Stabb, E.V., 2005. Culture-independent characterization of the microbiota of the ant lion Myrmeleon mobilis (Neuroptera: Myrmeleontidae). Applied and Environmental Microbiology 71, 8784-8794.

Enya, J., Koitabashi, M., Shinohara, H., Yoshida, S., Tsukiboshi, H., Negishi, H., Suyama, K., Tsushima, S., 2007. Phylogenetic diversities of dominant culturable Bacillus, Pseudomonas and Pantoea species on tomato leaves and their possibility as biological control agents. Journal of Phytopathology 155, 446-453. 
M.B. Blackburn et al./ Biological Control 46 (2008) 434-441

441

Garbeva, P., van Overbeek, L.S., van Vuurde, J.W.L., van Elsas, J.D., 2001. Analysis of endophytic bacterial communities of potato by plating and denaturing gradient gel electrophoresis (DGGE) of 165 rDNA Based PCR Fragments. Microbial Ecology 41, 369-383.

Holmes, B., Owen, R.J., McMeekin, T.A., 1984. Genus Flavobacterium Bergey, Harrison, Breed, Hammer and Hinton 1923, 97 ${ }^{\mathrm{AL}}$. In: Grieg, N.R., Holt, J.G. (Eds.), Bergey's Manual of Systematic Bacteriology, vol. 1. The Williams and Wilkins Co., Baltimore, MD, pp. 353-361.

Kwon, S.W., Kim, J.S., Park, I.C., Yoon, S.H., Park, D.H., Liz, C.K., Go, S.J., 2003. Pseudomonas koreensis sp. nov., Pseudomonas umsongensis sp. nov. and Pseudomonas jinjuensis sp. nov., novel species from farm soils in Korea. International Journal of Systematic and Evolutionary Microbiology 53, 21-27.

Lee, I.M., Hammond, R.W., Davis, R.E., Gundersen, D.E., 1993. Universal amplification and analysis of pathogen 16S rONA for classification and identification of mycoplasma like organisms. Molecular Plant Pathology 83, 834-842.

Martin, P.A.W., 2002. An in vitro inhibition test that predicts toxicity of bacterial pathogen combinations in the Colorado potato beetle. Biocontrol Science and Technology 12, 643-647.

Morton, T.C., Vencl, F.V., 1998. Larval beetles form a defense from recycled hostplant chemicals discharged as fecal wastes. Journal of Chemical Ecology 24, 765-785.

Nishiwaki, H., Ito, K., Shimomura, M., Nakashima, K., Matsuda, K., 2007. Insecticidal bacteria isolated from predatory larvae of the antlion species Myrmeleon bore (Neuroptera: Myrmeleontidae). Journal of Invertebrate Pathology 96, 80-88.
Palleroni, N.J., 1984. Genus I. Pseudomonas Migula 1894, 237 ${ }^{\mathrm{AL}}$. In: Krieg, N.R., Holt, J.G. (Eds.), Bergey's Manual of Systematic Bacteriology, vol. 1. The Williams and Wilkins Co., Baltimore, MD, pp. 141-199.

Reiter, B., Pfeifer, U., Schwab, H., Sessitsch, A., 2002. Response of endophytic bacterial communities in potato plants to infection with Erwinia carotovora subsp. atroseptica. Applied and Environmental Microbiology 68, 2261-2268.

SAS Institute, 2006. SAS 9.1.3. Cary, NC.

Sessitsch, A., Reiter, B., Berg, G., 2004. Endophytic bacterial communities of fieldgrown potato plants and their plant-growth-promoting and antagonistic abilities. Canadian Journal of Microbiology 50, 239-249.

Steinhaus, E.A., 1941. A study of the bacteria associated with thirty species of insects. Journal of Bacteriology 42, 757-790.

Sturz, A.V., Christie, B.R., Matheson, B.G., 1998. Associations of bacterial endophyte populations from red clover and potato crops with potential for beneficial allelopathy. Canadian Journal of Microbiology 44, 162-167.

Sturz, A.V., Matheson, B.G., 1996. Populations of endophytic bacteria which influence host-resistance to Erwinia-induced bacterial soft rot in potato tubers. Plant and Soil 184, 265-271.

Vasanthakumar, A., Delalibera, I., Handelsman, J., Klepzig, K.D., Schloss, P.D., Raffa, K.F., 2006. Characterization of gut-associated bacteria in larvae and adults of the southern pine beetle, Dendroctonus frontalis Zimmerman. Environmental Entomology 35, 1710-1717.

Wright, S.A.I., Zumoff, C.H., Schneider, L., Beer, S.V., 2001. Pantoea agglomerans strain EH318 produces two antibiotics that inhibit Erwinia amylovora in vito. Applied and Environmental Microbiology 67, 284-292. 